\title{
A pontuação e a constituição de sentidos: um estudo dialógico em texto midiático impresso ${ }^{1}$
}

\author{
The punctuation and the constitution of \\ senses: a dialogic study of mediatic \\ printed text
}

Anderson Cristiano da Silva*

Secretaria de Educação do Estado de São Paulo

São Paulo - São Paulo / Brasil

\begin{abstract}
RESUMO: Este trabalho tem por objetivo discutir a ação dos sinais de pontuação e a influência deste conteúdo na constituição de sentidos no texto midiático impresso. Assim, para efeito de análise, utilizamos um corpus constituído de um artigo opinativo do colunista Clóvis Rossi (Folha de S. Paulo), tendo como referencial teórico-metodológico alguns pressupostos bakhtinianos, principalmente a dialogia constitutiva da linguagem. Especificamente nesta pesquisa, discutimos o emprego dos parênteses, sendo considerados marcas relevantes na interação entre (inter)locutores. Confirmando nossa hipótese, observamos que a pontuação contribui também para revelar traços de subjetividade, bem como as propriedades dialógicas do enunciado.

PALAVRAS-CHAVE: sinais de pontuação, viés bakhtiniano, constituição de sentidos.

ABSTRACT: This paper aims to discuss the action of the punctuation marks and the influence of this content in the constitution of senses in the mediatic printed text. We analyzed a corpus consisted of a newspaper article written by Clóvis Rossi (Folha de S. Paulo) under the light of some Bakhtin's principles. Specifically in this research, we discuss the use of brackets, being considered excellent marks in the interaction between speaker and interlocutor. Confirming our hypothesis, we observed that punctuation also contributes to reveal subjectivity traces, as well as the dialogic properties of statements.

KEYWORDS: punctuation marks, Bakhtinian view, meaning.
\end{abstract}

\footnotetext{
*andcs@ig.com.br

${ }^{1}$ Este artigo apresenta resultados da dissertação de mestrado "A pontuação e os efeitos de sentido: um estudo sob o viés bakhtiniano", defendida no Programa de Pós-graduação em Linguística Aplicada da UNITAU, em 2009, sob a orientação da Profa. Dra. Miriam Bauab Puzzo.
} 


\section{Introdução}

Verificamos em nossa prática docente que muitos educandos não têm uma compreensão fundamentada sobre o emprego dos sinais de pontuação. Percebemos também que o ensino e aprendizagem desse conteúdo ainda continuam atrelados apenas a funções de ordem sintática, associadas às prescrições dos manuais de gramática ou livros didáticos; que valorizam as inúmeras regras e não conseguem abarcar a presença dos sujeitos da enunciação, sujeitos esses que constroem o enunciado a partir das constituições subjetivas.

Sob outro aspecto, percebe-se uma dualidade no discurso presente na escola referente ao ensino e aprendizagem dos sinais de pontuação, uma vez que nos parece não haver um ensino eficaz para este tópico gramatical, tampouco a difusão de novas maneiras para se trabalhar com esse conteúdo. A relação da pontuação com as nomenclaturas sintáticas não parece tão producente, pois, antes de aprender a pontuar, seria necessário um domínio maior das estruturas sintáticas, estando um assunto ligado ao outro.

Se não houver um trabalho de esclarecimento sobre a importância desse conteúdo para a constituição de sentidos, os educandos ficam fadados a pontuar sem nenhum parâmetro e dessa maneira, recorrer à intuição ou às regras pouco ortodoxas. Desse modo também, a perpetuação desse tipo de prática ratifica nossa proposta de investigação, pois procuramos desvincular a ideia do ensino e aprendizagem da pontuação única e exclusivamente por regras prescritivas ou nomenclaturas de ordem sintática (SILVA, 2009).

$\mathrm{Na}$ tentativa de deslocar o enfoque dessa prática, resolvemos trabalhar em uma perspectiva enunciativo-discursiva, trazendo um exemplo da linguagem em uso e, para tal finalidade, escolhemos utilizar um artigo opinativo da esfera jornalística veiculado em uma mídia impressa de grande circulação (Folha de S. Paulo). Ademais, soma-se o papel social da esfera midiática e sua importância na formação de leitores fluentes e críticos, uma vez que proporciona um material muito rico para investigação da linguagem em funcionamento, bem como os sentidos advindos da interação entre (inter)locutores.

Com o desenvolvimento dessa nova proposta em olhar os sinais de pontuação, nosso desafio é destacar a relação dialógica que os enunciados mantêm com o momento sócio-histórico e as possíveis atitudes responsivas engendradas na inter-relação entre locutor e público leitor, também a partir da pontuação existente na superfície textual. Isso posto, espera-se ampliar os horizontes sobre o emprego da pontuação a partir da perspectiva discursiva proposta por Bakhtin. 


\section{O dialogismo e outros preceitos como subsídios para uma análise enunciativo-discursiva}

Ao elencarmos trabalhar com uma análise de excertos provindos da mídia impressa, a teoria bakhtiniana revela-se adequada a este procedimento. Com efeito, faz-se pertinente uma breve revisão sobre quais pressupostos teóricos iremos nos ancorar no desenvolvimento desta investigação.

Assim, na obra de Bakhtin $(1997,2003)$, percebemos a tentativa de relacionar explicitamente a linguagem e a sociedade, considerando o signo como produto da interação social. Por sua vez, as ideias do teórico russo vêm somar com o nosso ponto de vista sobre o trabalho com a pontuação numa abordagem dialógica, pois a visão bakhtiniana apresenta-nos o viés discursivo como um dos caminhos para análise dos enunciados em circulação.

Além disso, cabe-nos citar duas questões que envolvem as análises de nossa pesquisa e que fazem parte de todo enunciado: o tempo e o espaço. A complexa relação que se estabelece na interação verbal requer um acabamento que só pode vir do exterior pelo olhar do outro, mas a "ponte" que liga os (inter)locutores materializa-se em outro tempo / espaço.

Existe uma analogia quase total entre significados das fronteiras temporais e espaciais na autoconsciência e na consciência do outro. $\mathrm{O}$ exame fenomenológico e a descrição do autovivenciamento e do vivenciamento do outro, tendo em vista que a genuinidade dessa descrição não é turvada pela inserção de generalizações e leis teóricas (em linhas gerais, o homem é uma equação do eu e do outro, um desvio em face das significaçõos axiológicas), revelam nitidamente a diferença essencial que tem o significado do tempo na organização do meu autovivenciamento e do vivenciamento do outro por mim. O outro está mais intimamente ligado ao tempo (não se trata, claro, do tempo elaborado pela matemática nem pelas ciências naturais, pois isto subentenderia uma generalização correspondente do homem), está por inteiro inserido no tempo como o está inteiramente no espaço, no vivenciamento dele por mim nada perturba a temporalidade contínua de sua existência. Eu não estou para mim mesmo inteiramente no tempo, mas "minha maior parte" é vivenciada intuitivamente por minha própria pessoa fora do tempo, eu disponho de um apoio imediatamente dado no sentido. (BAKHTIN, 2003, p. 99-100).

Nesse contexto, Bakhtin vem nos trazer a noção de cronotopia (tempo) e exotopia (espaço), cujos conceitos são imprescindíveis para se compreender um corpus pelo viés bakhtiniano. Quando se propõe analisar a constituição de 
sentidos por meio da pontuação, ao mesmo tempo, considera-se também o acabamento do enunciado. Este acabamento é um ato no qual tempo / espaço são fatores pertinentes da relação entre os participantes do discurso.

Sob essa perspectiva, a interação social dá-se de diferentes maneiras e se pensarmos no caso da relação entre signos linguísticos e sinais de pontuação, esses são elementos constitutivos do texto impresso e possuem uma grande importância na constituição dos sentidos. Assim, percebe-se a construção dos sentidos por meio da materialidade linguística, pois "tudo está na superfície, tudo está na troca, tudo está no material, principalmente no material verbal" (BAKHTIN, 1997, p.42).

Consoante aos preceitos de Bakhtin, esta pesquisa tratou dos esquemas de comunicação verbal de forma a privilegiar a interação existente neste processo, considerando o papel ativo dos (inter)locutores no fluxo verbal.

A propósito de nossas discussões, podemos pensar que um artigo opinativo que tem grande circulação na sociedade é passível de inúmeras leituras, tendo em vista que os interlocutores podem atribuir tons valorativoemocionais diferentes, dependendo das escolhas lexicais do locutor, bem como inferir que as escolhas por determinada pontuação influenciam, da mesma maneira, na compreensão e recepção do enunciado. Com efeito, "cada enunciado é uma resposta, contém sempre, com maior ou menor nitidez, a indicação de um acordo ou de um desacordo; é um elo da corrente ininterrupta da comunicação sociocultural" (FARACO, 2009, p.59).

Essa atitude dialógica pode ser considerada em ambos os casos: tanto na ação verbal oral, em que os falantes estão presentes, como no caso do discurso escrito, em que os interlocutores estão separados por um suporte de comunicação. Em ambas as ocorrências, há uma complexa rede interacional, pois as vozes verbais constitutivas dos sujeitos se entrelaçam para dar acabamento ao enunciado.

Os limites de cada enunciado concreto como unidade de comunicação discursiva são definidos pela alternância dos sujeitos do discurso, ou seja, pela alternância dos falantes. Todo enunciado - da réplica sucinta (monovocal) do diálogo cotidiano ao grande romance ou tratado científico - tem, por assim dizer, um princípio absoluto e um fim absoluto: antes do seu início, os enunciados de outros; depois de seu término, os enunciados responsivos de outros (ou ao menos uma compreensão ativamente responsiva baseada nessa compreensão). $\mathrm{O}$ falante termina o seu enunciado para passar a palavra ao outro ou dar lugar à sua compreensão ativamente responsiva. (BAKHTIN, 2003, p. 275). 
Em consonância com tais colocações, o entendimento do dialogismo encontrado na obra de Bakhtin é um dos conceitos-chave que contribui para nossa pesquisa. Apesar de os estudos bakhtinianos concentrarem-se nos textos literários, sua visão dialógica de linguagem vem corroborar na compreensão do relacionamento existente entre os textos, dos quais a pontuação é parte intrínseca. Resumidamente, pode-se dizer que o dialogismo constitui-se como um dos elementos unificadores do pensamento bakhtiniano, com esse conceito funda-se a propriedade dialógica da língua (FIORIN, 2006).

Segundo Barros (1994), só se pode apreender o dialogismo como algo interacional pelo deslocamento do conceito de sujeito. Para Bakhtin, o sujeito é visto como sujeito discursivo, pois é formado pelos discursos, nos quais estão presentes diferentes vozes sociais. Quando escreve, o locutor tem dentro de si a imagem do outro e por isso ele escolhe a palavra e até mesmo o tipo de pontuação que atingirá seu leitor. Esse processo parece ser algo inconsciente, mas, ao construir ideologicamente seu discurso, o sujeito-autor pauta-se pela alteridade, imaginando uma atitude responsiva de seus prováveis leitores (BAKHTIN, 2001).

Isso posto, ao analisarmos os efeitos de sentido em um texto opinativo, temos que levar em consideração a questão dialógica, uma vez que a compreendemos como parte inerente a todo o enunciado. Além disso, se pensarmos que o texto presente nos jornais exibe julgamentos de valor e matizes diferentes (VOLOSHINOV, s.d.), é necessário considerar também a situação extraverbal que envolve os enunciados com base nos índices discursivos, dos quais ressaltamos o uso da pontuação.

\section{O texto midiático impresso sob à luz da Análise Dialógica do Discurso}

Analisar textos de comunicação é uma atividade complexa, pois requer um embasamento teórico-metodológico cuja finalidade é a leitura crítica. Essa habilidade deveria ser uma característica de todo leitor, principalmente de educadores de língua materna. Nessa abordagem, o emprego da pontuação é um elemento importante para a constituição de sentidos, pois aparentemente não há um único sentido para o enunciado e é necessário que o interlocutor reconstrua alguns processos para interagir com o momento de enunciação.

Com base na constatação de que não existe uma objetividade absoluta nos textos impressos, mas verdades aproximadas, cabe ao pesquisador o trabalho de fornecer subsídios instrumentais para pesquisas que tratam das 
manifestações linguístico-discursivas. Assim sendo, este trabalho insere-se numa perspectiva teórico-metodológica da Análise Dialógica do Discurso (ADD), conforme os preceitos de Bakhtin. A partir desse fio norteador, propomo-nos explicitar a contribuição de alguns conceitos bakhtinianos para a pesquisa nas ciências humanas (AMORIM, 2004) e as análises que nos dispusemos a fazer. Com efeito, a ADD nos ampara no sentido de compreender a constituição e funcionamento do discurso e da subjetividade inerente a todo enunciado, ampliando assim nossa percepção sobre os textos de mídia impressa.

Desse modo, se pensarmos no processo de escrita, tanto na redação de um artigo opinativo quanto de qualquer outro gênero, temos associada a voz de um outro. Por existir o princípio da responsividade, há também a possibilidade de mudança de sentidos e a observação das diferentes vozes que compõem o texto.

Por conseguinte, quando deixamos nossa linguagem no papel e com ela a pontuação, estamos já pensando em um outro (o que nos remete também ao conceito de atitude responsiva). Esse outro é essencial em nossa pesquisa, pois se pensarmos na constituição de sentidos, temos que creditar o ato de intelecção à interação entre os participantes do discurso.

Além disso, as concepções engendradas pelo Círculo bakhtiniano foram essenciais para o desenvolvimento no campo das ciências humanas, principalmente na área da linguística, pois a visão que se tinha da língua (como instrumento) foi alterada com a inserção de novos conceitos dentro desse campo de estudo (OLIVEIRA, 2002), no qual podemos citar as concepções de ideologia e dialogismo.

Ao discutirmos a constituição de sentidos que os sinais de pontuação podem causar no texto, temos que considerar que os signos linguísticos não são apenas instrumentos, mas parte de um processo dialógico que é permeado pela ideologia, além de considerar o sujeito como um elemento importante na análise do discurso.

Especificamente sobre nosso material de investigação, o corpus desta pesquisa constitui-se de um artigo opinativo retirado do jornal Folha de $S$. Paulo. Ademais, a escolha por textos desse jornal justifica-se por sua importância no contexto nacional, pois é considerado um dos maiores periódicos do país.

Sob outro aspecto, o estudo de textos midiáticos compreende o reconhecimento do caráter material e simbólico no qual eles estão inseridos, além disso, requer a reflexão da mutabilidade espaço-temporal a partir do deslocamento enunciativo. 
É precisamente por que a inconclusibilidade e a maleabilidade são inerentes às personalidades vivas, aos acontecimentos cotidianos e aos parâmetros espaço-temporais que a realização (não o reconhecimento, não a descoberta, mas precisamente a realização) de uma totalidade é tão indispensável - e, portanto, carregada de responsabilidades. A totalidade de qualquer coisa só pode ser observada de uma posição que lhe é exterior no espaço e posterior no tempo. Mas, dado que uma totalidade pode ser percebida de uma infinidade de ângulos diferentes (e cada uma dessas percepçôes só será plenamente reconhecido como tal por "aquele que a conclui"), o sentido da totalidade é sempre "atribuído" e não decretado ou revelado. (EMERSON, 2003, p. 267-8).

Corroborando o excerto acima, como é de consenso, a aceitação ou não de determinado discurso depende da constituição subjetiva, uma vez que "nossas respostas à mídia, tanto em particular como em geral, variam por indivíduo e segundo os grupos sociais de acordo com sexo, idade, classe, etnia, nacionalidade, assim como ao longo do tempo" (SILVERSTONE, 2002, p. 27).

A interação entre os participantes do discurso passa pelo suporte midiático e isso abre margem para desvios de sentido, pois representa refletir sobre a composição subjetiva de cada indivíduo e a opacidade dos meios pelos quais o enunciado circula. Nesse questionamento sobre a mídia, os meios de comunicação de massa representam um espaço no qual os significados não são estáveis, pois os enunciados são transpostos e isso acarreta alteração na constituição de sentidos.

De acordo com essas observações, pode-se concluir que a informação não está correlacionada unicamente à intenção do locutor, nem tampouco pelo interlocutor, mas resulta de uma cointencionalidade que desponta nos enunciados os efeitos desejados, possíveis e produzidos. Além disso, a interpretação é um fenômeno social e, como tal, deve ser analisada com critério, pois abarca a linguagem manifestada dentro de um determinado gênero e de uma determinada condição sócio-histórica.

Mesmo quando se tenta fazer um texto transparente e objetivo, a escolha do léxico e da própria pontuação já denota um tipo de posicionamento subjetivo diante de um assunto, uma vez que somos seres de linguagem, estamos submetidos às ideologias e também somos atravessados por diferentes vozes, o que nos constitui como sujeitos heterogêneos.

Quando se imagina um texto que terá uma grande circulação, há de se esperar que haja a construção de diferentes sentidos, pois "a informação midiática fica prejudicada porque os efeitos visados, correspondentes às 
intenções da fonte de informação, não coincidem necessariamente com os efeitos produzidos no alvo" (CHARAUDEAU, 2006, p.59).

Como o enfoque de análise deste trabalho é um artigo opinativo publicado na Folha de S. Paulo, interessa-nos discutir sobre as características do ambiente midiático que envolvem esse enunciado. No que tange ao estudo desse gênero, os textos opinativos impressos e divulgados pela Folha de S. Paulo possuem um histórico editorial e marcas ideológicas que influenciam o perfil de seus assinantes e leitores. Os articulistas desse periódico também são constituídos por essas implicações, o que se revela pela subjetividade presente na materialidade linguística.

Nesse ponto, os sinais de pontuação também podem revelar traços de subjetividade, pois a escolha por determinado sinal não depende apenas das normas instituídas, mas estão ligadas às escolhas estilísticas de cada indivíduo. Seguindo esse raciocínio, observamos também que os manuais que regem a maneira de escrever dos grandes periódicos não dão conta da dinâmica em que a língua materna é proferida e, nisso, incluímos as possibilidades de pontuação que um texto pode apresentar.

A partir dessas afirmações, acreditamos também que muitos jornalistas e pessoas que trabalham com a mídia impressa sintam essa dicotomia em aceitar passivamente a prescrição dos manuais de redação. Mesmo no caso de uma aceitação das regras, o texto constitui-se também da subjetividade de cada indivíduo.

Em contrapartida, segundo o manual da Folha (1987), os colaboradores do jornal devem poupar trabalho ao leitor, tentando deixar o texto o mais claro possível, sem imaginar, supor ou julgar um conhecimento prévio que o leitor possa ter sobre $\mathrm{o}$ assunto em discussão. Mesmo com essa intenção padronizadora, existem elementos que escapam a qualquer prescrição de manuais de redação e é sobre esse aspecto que nos propomos a refletir em nossa pesquisa.

O manual de redação da Folha admite também a inexistência de uma objetividade em textos jornalísticos, pois reconhece a presença da subjetividade no processo de criação, tendo em vista que "ao redigir um texto e editá-lo, o jornalista toma uma série de decisões que são em larga medida subjetivas, influenciadas por suas posições pessoais, hábitos e emoçōes" (FOLHA DE S. PAULO, 1987, p. 34). De outro modo, o periódico orienta os colaboradores a procurarem uma objetividade possível por meio de vários procedimentos. Dessa forma, o possível não significa uma objetividade absoluta, mas uma busca por ela. 
Considerando todo esse contexto sócio-histórico citado é que nos dispusemos a centrar nosso discurso no emprego da pontuação e uso específico desse recurso textual no texto opinativo veiculado em mídia impressa.

\section{Reflexões sobre o uso dos parênteses}

Após discorrermos sobre o embasamento teórico-metodológico que ancora esta pesquisa, achamos por bem explicitar algumas concepções que se creditam aos sinais de pontuação. O que devemos notar na pesquisa em questão é que a preocupação de nosso estudo não são as regras normativas, mas uma análise que tenta dissociar a pontuação dos atos de comunicação. Dahlet confirma este pensamento dizendo que "pouquíssimos sinais de pontuação ficam regidos pela norma enquanto a maioria decorre da intenção de comunicação ou da interação estabelecida entre quem escreve e quem lê" (2006, p. 24).

De igual modo, na investigação que nos propusemos a fazer, acreditamos que para alcançar certo domínio sobre as regras de pontuar há necessidade das pessoas reconhecerem a importância que os sinais de pontuação exercem em toda estrutura textual e na constituição de sentidos. Além disso, "[n]em tudo se pode ensinar em matéria de pontuação, exatamente porque ela tem muito de pessoal, de gostos, de predileçôes" (LAURIA, 1989, p.2).

Sob o enfoque normativo, Cegalla (2000) define ser tríplice a finalidade dos sinais de pontuação. De acordo com esse autor, a pontuação serve para: assinalar as pausas e as inflexões da voz (a entonação) na leitura; separar palavras, expressōes e oraçôes que devem ser destacadas; esclarecer o sentido da frase, afastando qualquer ambiguidade. No entanto, não há uniformidade entre os escritores quanto ao emprego dos sinais de pontuação, não sendo possível traçar normas rigorosas sobre o conteúdo.

De maneira diferente, podemos encontrar outra definição que a pontuação recebe. Conforme a descrição de um dicionário gramatical, a pontuação é concebida como:

Sistema de sinais gráficos que serve, entre outros, para: 1. marcar as diversas modalidades de entonação da língua oral. 2. marcar a intenção do autor. 3 orientar o leitor, na língua escrita, no relacionamento entre frases, períodos e o texto como um todo. 4. separar no discurso direto e no diálogo as falas do narrador e/ou do(s) personagem (ns). 5. separar e/ou realçar palavra, expressão, frase. (GIACOMOZZI et al., 2004, p.229). 
Observando o enfoque sobre o conteúdo, pode-se observar a preocupação com outras questões que remetem diretamente sobre a constituição dos sentidos, apresentando, assim, diferenças com relação à gramática exposta anteriormente.

As perspectivas apresentadas (CEGALLA, 2000; GIACOMOZZI $e t$ al., 2004) confirmam que os sinais de pontuação ainda continuam sendo vistos atrelados estritamente por orientações prescritivas, muitas vezes complexas, o que acaba resultando numa aprendizagem improdutiva e ineficaz.

Por fazer parte do discurso, a pontuação é um instrumento importante, uma vez que agiliza a compreensão de acordo com o que o autor pretende dizer. Além disso, os sinais de pontuação dão ritmo ao texto e permitem a fluidez na leitura. O que nos preocupa é a falta de importância que se dá aos sinais de pontuação, pois eles estão presentes em todo texto escrito e representam algo fundamental para a constituição de sentidos. Corroborando este raciocínio, a pontuação pode ser considerada como:

Instrumento ou agente do ritmo, do poder, do silêncio em todas as suas dimensões, a pontuação resiste, reclama que se escreva sua história, que se precisem as táticas; que se mostrem como suas nuanças são constituidoras de toda interrogação sobre a língua. (DURRENMATT, 2000, p.3, tradução nossa).

Segundo Durrenmatt, "a pontuação causa medo por estar presente em tudo e também por sua aparente insignificância” (2000, p.3, tradução nossa). Esse pensamento permite-nos refletir sobre a onipresença dos sinais de pontuação no texto escrito, pois a aparente insignificância não se faz correspondente, como ressaltamos até aqui.

Consoantes ao exposto até aqui, pretendemos trazer à tona a discussão sobre as nuanças de tom pelo uso da pontuação na língua escrita, limitandonos a refletir sobre os parênteses. Ratificando nossa predileção, como há uma complexidade no uso das diversas pontuações, restringimo-nos a discutir com mais acuidade os efeitos de sentido proporcionados pela presença dos parênteses no fio do discurso.

Sobre o uso dessa pontuação, encontramos apenas duas recomendações, uma relacionada ao uso para isolamento de palavras, locuçóes ou frases intercaladas no período; outra relacionada à possibilidade de substituição da vírgula ou do travessão (CEGALLA, 2000). Já em Giacomozzi et al. (2004), encontramos quatro orientações para o emprego dos parênteses: 1) a separação 
de elementos intercalados do restante da frase; 2) a marcação, no teatro, do que o ator deve fazer; 3) a inserção de citações; 4) indicação que a palavra ou frase foi escrita ou proferida daquela forma, contrariando a norma culta ou a opinião do escritor.

Considerando que parênteses são sinais de pontuação "relativamente fáceis" em sua utilização (se comparados a outros sinais de pontuação), observase que a definição dada em manuais de gramática não conseguem abarcar toda a funcionalidade desse sinal. Nesse sentido, Laurens explicita-nos que os parênteses são uma das maneiras de representar a essência de um escritor e sua subjetividade, delegando a esses sinais a forma figurada de alma do texto. De acordo com a autora:

Os parênteses compreendem tudo o que ainda não foi dito (ou tão mal), tudo o que não corresponde ao sentido, tudo o que é necessário ir buscar longe, atrás das aparências. Os parênteses, como as palmas em volta de um rosto amado, inserem então o que conta mais que tudo: a imaginação, o desejo, o humor, o inconsciente, o inusitado. (LAURENS, 2000, p. 231, tradução nossa).

Nesse aspecto, os parênteses (d)enunciam a aparente homogeneidade do texto, porque "penetram na fala em um sentido mais profundo, mais verdadeiro, mais justo; rompendo a aparente facilidade da linguagem, eles fazem surgir o que não se esperava, mas, ao qual se dá valor: um sopro de ar, uma respiração nova" (LAURENS, 2000, p.231, tradução nossa).

Assim, os sinais de parênteses vêm contribuir para a percepção da subjetividade inerente à materialidade linguística, podendo ser comparado a um órgão do corpo humano que trabalha em harmonia com outros órgãos para manutenção da vida.

Eles se abrem e se fecham, de fato, tais como pulmões em atividade, alimentando o pensamento que ameaçava enfraquecer-se; eles injetam ao texto o oxigênio necessário à sua densidade - a dúvida, a hesitação, o detalhe: o parêntese é a apoteose da nuança, aqui está sua força e seu gênio. (LAURENS, 2000, p. 231, tradução nossa).

Dessa forma, uma das funções dos parênteses está na capacidade que eles têm de dar liberdade à escrita, possibilitando explicitar hesitações, informações fora do texto ou mesmo indicando modos de sentir e perceber os fatos sem comprometer a objetividade do texto em si. 
Sob esse aspecto, é fato que o enunciador também trabalha seus pontos de subjetivação por meio dos sinais de pontuação. Nesse caso, as marcas deixadas por este recurso da língua deixam transparecer a incompletude da linguagem e os tons valorativo-emocionais.

\section{Análise do corpus: o uso dos parênteses na superfície textual}

A partir da exposição teórico-metodológica, utilizamos para esta discussão um artigo opinativo do caderno de Opinião da Folha de São Paulo (FSP), do Colunista Clóvis Rossi, um renomado formador de opinião desse periódico; além disso, o jornalista, por possuir um espaço fixo nessa mídia (Caderno Opinião), tece periodicamente seu discurso focado nos fatos políticos e econômicos de âmbito nacional e internacional. Ressaltamos também que Rossi é um correspondente de prestígio, pois continuamente é enviado para diversos lugares do mundo no intuito de acompanhar (e reportar) os grandes eventos sociopolíticos que norteiam a economia mundial.

Se pensarmos que determinado suplemento (caderno) da Folha atinge um público-alvo específico, o mesmo já não ocorre com tanta homogeneidade no espaço destinado às opiniōes. Por ser um espaço estratégico no jornal, no qual se encontram também o editorial e a opinião de outros colunistas e leitores já no início do jornal. Acreditamos que o espaço tenha um número muito maior e heterogêneo do que em cadernos que tratam de assuntos específicos, como economia, esporte ou cultura.

Clóvis Rossi compartilha seu enunciado em um espaço de prestígio, cujos enunciados atingem um número diversificado de segmentos da sociedade. Dessa maneira, ao elaborar seu texto, Rossi precisa considerar a atitude responsiva dos prováveis leitores de sua coluna, tais como políticos, intelectuais e os diversos profissionais que se interessam por assuntos da área econômica e política. Além disso, o locutor tem noção de que seu poder de influência como formador de opinião o responsabiliza a produzir um discurso mais objetivo e direto.

Nos seus enunciados, observa-se que o autor deixa transparecer fragmentos do ethos discursivo e os tons valorativo-emocionais na construção do texto, uma vez que algumas pistas no fio do discurso ajudam a evidenciar a presença de outras vozes na materialidade linguística. Dessa forma, ratificamos que a subjetividade é algo inerente a qualquer análise que pretendemos fazer sob o viés bakhtiniano. 
Assim, antes da nossa discussão sobre excertos específicos do corpus, reproduzimos abaixo o artigo completo de Rossi:

\section{AUSENCIAS QUE PREENCHEM LACUNAS}

SÃO PAULO - A Bélgica está sem governo há uns quatro meses. Divergências entre os partidos da francófona Valônia e da flamenga Flandres. Por "sem governo" entenda-se a superestrutura política, o gabinete. $\mathrm{O}$ resto funciona.

Os policiais policiam, os impostos são cobrados (ou sonegados) como de costume, os trens chegam e saem mais ou menos no horário, o metrô roda placidamente, tão placidamente que nem catracas tem, continuam à venda em cada esquina os imperdíveis "graufes" ("waffels", feitos na hora, até fumegam à primeira mordida).

Imagine situação similar no Brasil (calma, "zelites", não estou falando do atual governo, mas de qualquer governo).

Digamos que o ministro da Fazenda saia e não seja designado substituto. Caem os juros? Depende do Banco Central, que já mostrou que não dá a menor bola nem para o presidente, quanto mais para um subordinado como o ministro.

$\mathrm{E}$ as exportações, aumentam ou diminuem? Vale lembrar o óbvio: governos não exportam; empresas exportam. Logo...

Digamos ainda que o ministro da Saúde tire férias de uns três anos. Aumenta o número de mosquitos da dengue? Não depende dele, diz a propaganda do próprio governo, mas de todos nós. Logo...

Sai o ministro de Minas e Energia. Ah, já saiu faz tempo e não foi substituído? Então deixa pra lá.

Sem governo, o Corinthians sai da zona de rebaixamento? Depende do Lulinha, não do Lula (Lulinha o jogador, não o filho do presidente).

Ah, tem um quesito em que governo é de fato decisivo: sem governo, o senador Renan Calheiros teria sido cassado.

Se é assim, um brinde para a Bélgica, até porque, com ou sem governo, continua fabricando e vendendo 717 marcas de cerveja. Mas beba com moderação que amanhã é segunda, tem governo, tem dengue e tem juros.

ROSSI, Clóvis. Ausências que preenchem lacunas. Caderno de Opinião. A2. Folha de S. Paulo, São Paulo, 21 out. 2007. 
Antes de fazer qualquer reflexão sobre a relação existente entre os signos linguísticos e os sinais de pontuação, fazem-se necessárias a contextualização temática e as condições de produção que envolvem o discurso. Em termos gerais, Rossi discorre sobre a continuidade e fluidez do serviço público na Bélgica, mesmo sem um governo fixo. Lá, todos os serviços funcionam normalmente. Em contrapartida, o autor propõe imaginarmos a mesma situação, só que no Brasil.

Ao relacionar a situação política da Bélgica e do Brasil, o autor explicita que mesmo com a desestrutura política existente na Bélgica (por um período de quatro meses), o país continuou funcionando normalmente. Já no Brasil, a superestrutura governamental representaria algo que emperra o país de se desenvolver como no primeiro mundo.

No mesmo caderno em que o artigo está vinculado, observam-se também temas importantes para debates, como violência da desigualdade e fontes de energia. Esses assuntos, discutidos por pessoas de destaque no meio acadêmico e político, corroboram o prestígio desse espaço no jornal, visto que também nesse caderno são noticiados diariamente os principais fatos do Brasil e do mundo.

Pontualmente sobre os assuntos que foram noticiados junto ao artigo opinativo do articulista, verificamos temas relacionados a irregularidades e ações políticas que emperram o desenvolvimento da nação, fatos esses que dialogam com a opinião explicitada por Clóvis Rossi. Dentre esses fatos, chamamos a atenção para o fortalecimento de blocos políticos com interesses próprios, como o caso da bancada ruralista no congresso. Além disso, a falta de fiscalização e as irregularidades nos gastos do governo ratificam e nos fazem refletir sobre a eficiência do governo brasileiro.

Em contrapartida, na mesma edição do caderno, na parte que se refere aos assuntos internacionais, verificamos a informação sobre a troca de membros-chave do partido comunista no Congresso da China. Essa atitude mostra a preocupação do governo chinês em solidificar sua administração, restabelecendo o grau de compromisso necessário entre as diferentes facçōes da legenda para governar o país.

Dessa forma, o interlocutor de Rossi, ao relacionar a temática do artigo com as demais notícias veiculadas no dia, pode ratificar dialogicamente a tese do jornalista sobre a maior competência de gestores internacionais, frente aos políticos brasileiros que comandam áreas estratégicas da nação.

A partir desse contexto, esta análise objetiva discutir particularmente a presença dos parênteses como elementos que possibilitam observar a 
constituição de sentidos. Dessa maneira, pelas escolhas lexicais e juntamente com a pontuação que acompanha o discurso de Rossi, pode-se perceber a manifestação subjetiva que envolve o artigo e influencia na constituição de sentidos.

Antes de entrarmos propriamente na análise dos parênteses, gostaríamos de discorrer sobre um fato que nos chamou a atenção. Já no início do artigo, verificamos uma relação dialógica explícita entre o título e o corpo do texto, uma vez que o locutor utiliza as reticências para dialogar com o título do texto (Ausências que preenchem lacuna), desvelando um silogismo inconcluso. Dessa maneira, essa relação entre os signos (linguísticos e ideográficos) manifesta a dinâmica da concepção bakhtiniana de responsividade, pois os sinais de pontuação contribuem na construção dos efeitos de sentido. Essa percepção da atitude responsiva é um ponto importante em nossas reflexões, uma vez que nos auxilia a compreender o caráter interativo existente na materialidade discursiva.

Assim sendo, ao elaborar o artigo, o autor termina dois parágrafos consecutivos utilizando as reticências, fato inusitado para esse tipo de texto. Para ilustrar essa construção enunciativa, vamos refletir separadamente sobre cada um dos excertos:

(a) E as exportações, aumentam ou diminuem? Vale lembrar o óbvio: governos não exportam; empresas exportam. Logo...

(b) Digamos ainda que o ministro da Saúde tire férias de uns três anos. Aumenta o número de mosquitos da dengue? Não depende dele, diz a propaganda do próprio governo, mas de todos nós. Logo...

No primeiro caso, quando o autor escreve (Logo...), a presença das reticências remete-nos a uma atitude responsiva que o locutor quer provocar intencionalmente. Rossi não conclui seu raciocínio, mas da forma que estrutura seus argumentos, leva o leitor a pensar na importância do governo para a cadeia produtiva. Do mesmo modo, no segundo parágrafo finalizado com as reticências, observa-se na trama linguística a intencionalidade de refletir sobre a responsabilidade dos órgãos nacionais e seu papel diante da população.

Como vimos, a pontuação é um recurso importante para a construção enunciativa, porém, como nosso enfoque não é analisar todos os seus sinais, continuaremos a discutir mais especificamente o uso dos parênteses. 
No texto de Rossi, no momento em que ele começa a dar exemplos do funcionamento eficaz da Bélgica sem uma superestrutura política fixa, observase a utilização dos parênteses em duas situações no mesmo parágrafo:

(c) Os policiais policiam, os impostos são cobrados (ou sonegados) como de costume, os trens chegam e saem mais ou menos no horário, o metrô roda placidamente, tão placidamente que nem catracas tem, continuam à venda em cada esquina os imperdíveis "gaufres" ("waffels", feitos na hora, até fumegam à primeira mordida).

Como sabemos, os parênteses são sinais de interação entre os interlocutores e também têm uma função semântica no discurso, permitindo-nos observar as variações de tom. Nesse sentido, na primeira ocorrência dos parênteses, a expressão "ou sonegados" já é um pressuposto existente, pois quer relembrar que também na Bélgica há cobranças e sonegações de impostos. Rossi estabelece uma relação dialógica, tentando reavivar a memória cultural do interlocutor.

Sob essas condições, considera-se o termo "ou sonegados" como uma expressão de destaque, uma vez que ao ser envolto pelos parênteses, estabelece uma duplicidade de leitura e impede um único modo de constituir os sentidos.

Dessa forma, ao estar destacado pelos parênteses, o sintagma acaba influindo na atitude responsiva do interlocutor. Ao discorrer que "os impostos são cobrados (ou sonegados) como de costume", Rossi sinaliza um tom irônico ao referir-se a costumeira prática de sonegação de impostos, carregando seu enunciado de juízos de valor e emoção.

Assim sendo, o ironista, o produtor da ironia, encontra formas de chamar a atenção do enunciatário para o discurso e, através desse procedimento, contar com sua adesão. Sem isso a ironia não se realiza. O conteúdo, portanto, estará subjetivamente assinalado por valores atribuídos pelo enunciador, mas apresentados de forma a exigir a participação do enunciatário, sua perspicácia para o enunciado e suas sinalizações, por vezes extremamente sutis. Essa participação é que instaura a intersubjetividade, pressupondo não apenas conhecimentos partilhados, mas também pontos de vista, valores pessoais ou cultural e socialmente comungados ou, ainda, constitutivos de um imaginário coletivo. É a organização discursivo-textual que vai permitir esse chamar a atenção sobre o enunciado e, especialmente, sobre o sujeito da enunciação. (BRAIT, 1996, p. 105). 
Esse acabamento valorativo-emocional remete ao interlocutor sua bagagem histórica, permitindo ou não sua adesão ao posicionamento adotado pelo locutor. Partindo dessa afirmação, o enunciado entre parênteses estabelece uma unidade de comunicação verbal heterogênea, com efeito, pode-se dizer que na constituição de sentidos, a relação mútua entre escritor e leitor estabelece uma complexa rede de interação no texto.

Retomando o mesmo parágrafo de análise, na segunda ocorrência dos parênteses, observamos que o locutor utiliza-os para explicitar o nome de um tipo de comida existente na Bélgica: "continuam à venda em cada esquina os imperdíveis 'gaufres' ('waffels', feitos na hora, até fumegam à primeira mordida)". Nesse caso, o autor, além de deixar claro o que são gaufres, também explica a maneira como são servidos.

Nessa utilização dos parênteses, Rossi também dialoga com o interlocutor, pois traz uma explicação de sua bagagem histórica, colocando experiências pessoais para contextualizar seu texto e persuadir seus prováveis leitores. Nesse ponto, há um apelo à percepção gustativa visual, pressupondo um leitor também sensível a esse apelo. A relação dialógica se estabelece nessa pressuposição partilhada em relação à cultura gastronômica. Assim, o autor, ao antecipar a atitude responsiva de seu interlocutor, considera não ser de conhecimento comum esse tipo de comida vendida nas ruas da Bélgica.

Diferentemente do primeiro termo destacado entre parênteses, esse enunciado remete-nos a um tom valorativo-emocional mais intimista, uma vez que, ao compartilhar as experiências vividas pelo enunciador-pessoa, o enunciador-autor tenta criar um laço de intimidade com seu leitor. Esses parênteses utilizados por Rossi têm a característica essencialmente bakhtiniana de estabelecimento da dialogia com os seus leitores, antecipando possíveis desconhecimentos por alguns e fornecendo-lhes informaçôes adicionais. O efeito de sentido possibilitado pelos parênteses é o de aproximação com os leitores.

Além disso, essa heterogeneidade revelada pelos parênteses, em ambos os excertos do parágrafo, poderiam ser retiradas sem grande prejuízo para o sentido, mas, no momento de enunciação, o autor deve ter achado pertinente a colocação desses excertos, tendo em vista as condiçóes de espaço / tempo dos participantes do discurso.

Observando outro caso, no terceiro parágrafo do artigo, Rossi estabelece uma relação dialógica mais direta com seus leitores, antecipando uma provável reação: "Imagine situação similar no Brasil (calma, "zelites", não estou falando do atual governo, mas de qualquer governo)”. Nessa situação, o autor não 
estabelece uma explicação, mas enuncia por um discurso direto uma provável interpretação que seus leitores possam ter frente às afirmações colocadas no texto opinativo. No fio do discurso, percebe-se que o colunista antecipa os possíveis julgamentos de valor de seu enunciado. Nessa situação, verificamos um tom de resguardo no qual Clóvis Rossi tenta preservar sua face frente aos prováveis julgamentos de seu artigo.

De outro modo, ao comparar a situação política do Brasil com o da Bélgica, temos que considerar o momento sócio-histórico em que a atual administração federal é controlada pelo partido petista. Nesse sentido, para não (d)enunciar sua posição política, Rossi se retrata afirmando que suas críticas são para qualquer governo e não apenas para o atual.

Um fato curioso que também nos chamou a atenção dentro do excerto marcado pelos parênteses, foi a inserção do neologismo "zelites". Em uma possível leitura, Rossi poderia ter aglutinado uma palavra conhecida, como "elite", ao termo intimista Zé. Nesse caso, o termo pode remeter-nos aos compadres, colegas e amigos que são nomeados para chefiar setores estratégicos do governo; também pode estar sinalizando um traço de oralidade às elites (zelites) como "os olhos" (zóios) na linguagem popular, o que nos remete a incorporação de uma outra voz que desabona os atuais mandatários da nação brasileira.

Dessa forma, a ideia de um leitor passivo, como um mero receptor da linguagem não pode ser considerada, uma vez que, na produção textual, há a preocupação com o outro, o que nos remete novamente à concepção bakhtiniana da atitude responsiva. Nesses termos, há o pressuposto de uma resposta de um leitor virtual, o qual se torna parte integrante do discurso.

No exemplo citado, observa-se que a subjetividade também se faz presente pelo uso da pontuação, uma vez que os efeitos de sentido são decorrentes da constituição subjetiva de cada sujeito, pois quem dá e atribui significado nas relações dialógicas são os (inter)locutores.

$\mathrm{Na}$ última ocorrência dos parênteses, situado no antepenúltimo parágrafo do artigo, verificamos novamente um tom de resguardo e ao mesmo tempo provocativo no enunciado de Rossi. Quando o colunista escreve: "Sem governo, o Corinthians sai da zona de rebaixamento? Depende do Lulinha, não do Lula (Lulinha o jogador, não o filho do presidente)", o trecho cita um time de futebol, no qual um dos torcedores mais ilustres é o próprio presidente da república. Além disso, ao citar o nome do jogador Lulinha, o autor prevê que sua escolha (do nome do jogador) pode remeter ao nome do filho do presidente, que responde também por Lulinha. 
Por conseguinte, esse excerto demarcado pelos parênteses pode deslocar o interlocutor a refletir sobre os benefícios que os apadrinhados do governo possuem, uma vez que não foi por acaso ou por ingenuidade que Clóvis Rossi colocou o nome desse jogador no artigo.

Para ratificar essa leitura do enunciado, recorremos ao parágrafo subsequente, no qual o autor diz: "Ah, tem um quesito em que o governo é de fato decisivo: sem governo, o senador Renan Calheiros teria sido cassado". Nesse caso, Rossi confirma apenas que uma das funções do governo é resguardar as ações ilícitas e ineficientes de seus correligionários. Com mais esse excerto, houve a possibilidade de perceber a importância que a pontuação exerce na constituição de sentidos e também como recurso dialógico no ato de interlocução.

Cabe ressaltar que as discussões levantadas até aqui apontam para um deslocamento na percepção dos sinais de pontuação, porém, por questão de espaço, limitamo-nos analisar apenas um pequeno artigo opinativo. Assim, recomendamos a observação do uso desse recurso de pontuação em diferentes textos para que o grau de pertinência e adequação das (futuras) análises sejam validadas, o que comprovamos em um trabalho mais amplo desenvolvido em nossa dissertação de mestrado.

\section{Considerações finais}

$\mathrm{Na}$ análise apreendida, percebemos que as relaçóes entre os signos linguísticos e os sinais de pontuação podem interferir na constituição de sentidos. Dessa forma, a pontuação revelou-se como um recurso dialógico importante. Assim, passa a evidenciar os significados, não só aqueles que o emissor almeja como também os construídos no processo de interação com os interlocutores.

Considerando o método tradicional de ensino desse conteúdo, percebemos a necessidade e a pertinência de uma análise pela abordagem discursivo-enunciativa, fazendo emergir as vozes sociais do emissor e dos possíveis leitores, não só em relação ao contexto imediato mas também ao leitor virtual. Desse modo, na trama do discurso, a pontuação acaba sendo um indicador da heteroglossia (cf. Bakhtin), cuja aparente objetividade é desvelada pelas diferentes vozes que constituem o evento enunciativo.

Em nosso corpus, a observação mais específica sobre os parênteses possibilitou-nos visualizar outras possibilidades de ensino e aprendizagem, além das que são utilizadas tradicionalmente. Essa reflexão permitiu-nos 
distanciar das regras que apregoam um uso simplista para os parênteses, e ao mesmo tempo, prescrevem um número de regras excessivas para a utilização das demais pontuações.

Corroborando a abordagem adotada, o estudo dos sinais de pontuação pelo viés bakhtiniano nos abre margem para um ensino diferenciado para esse conteúdo, dada a vasta contribuição engendrada pelo teórico russo. Essa perspectiva nos ampara em questôes que a gramática não dá conta, como é o caso do emprego da pontuação em textos da mídia impressa.

Nesse ponto, a questão da ironia, do tom, do ritmo e do grau de destaque sobre determinado sintagma está relacionado ao contexto em que o enunciado está inserido; nele também temos que considerar grau de responsividade presente no discurso e também a relação dialógica entre enunciados.

Enfim, é por conta de todas essas estratégias que poderemos iniciar as reflexões sobre a importância da pontuação na relação entre os enunciados e também na constituição de sentidos decorrentes da interação entre os signos linguísticos e os sinais de pontuação.

Finalmente, esperamos ter atingido nossos objetivos de ressaltar o uso da pontuação por caminhos que evoquem a questão do sentido. Nessa perspectiva, pretendeu-se auxiliar na construção de leitores mais proficientes. Além disso, almejou-se atingir (futuros) docentes, para que esses possam trabalhar os matizes que os sinais de pontuação exercem no texto escrito.

\section{Referências}

AMORIM, Marília. O pesquisador e seu outro: Bakhtin nas ciências humanas. São Paulo: Musa Editora, 2004.

BAKHTIN, Mikhail M. Estética da criação verbal. São Paulo: Martins Fontes, 1992.

BAKHTIN, Mikhail M. Estética da criação verbal. 4. ed. São Paulo: Martins Fontes, 2003.

BAKHTIN, Mikhail M. Marxismo e filosofia da linguagem. 8. ed. São Paulo: Editora HUCITEC, 1997.

BAKHTIN, Mikhail M. Freudismo. São Paulo: Editora Perspectiva, 2001.

BARROS, Diana Luz Pessoa de. Dialogismo, polifonia e enunciação. In: BARROS, Diana L. P de; FIORIN, José L. (Org.). Dialogismo, polifonia, intertextualidade: em torno de Bakhtin. São Paulo: Edusp, 1994. 
BRAIT, Beth. Ironia em perspectiva polifônica. Campinas: Editora da UNICAMP, 1996.

CEGALLA, Domingos Paschoal. Novíssima gramática da língua portuguesa. 43. ed. São Paulo: Companhia Editora Nacional, 2000.

CHARAUDEAU, Patrick. Discurso das mídias. São Paulo: Contexto, 2006.

DAHLET, Véronique. As (man)obras da pontuação: usos e significações. São Paulo: Associação Editorial Humanitas, 2006.

DURRENMATT, Jacques. (Org.). La ponctuation. Besançon: La Licorne, 2000.

EMERSON, Caryl. Os 100 primeiros anos de Mikhail Bakhtin. Trad. Pedro Jorgensen Jr. Rio de Janeiro: DIFEL, 2003.

FARACO, Carlos Alberto. Linguagem \& diálogo: as ideias linguísticas do círculo de Bakhtin. São Paulo: Parábola Editorial, 2009.

FIORIN, José Luiz. Introdução ao pensamento de Bakhtin. São Paulo: Ática, 2006.

FOLHA DE S. PAULO. Manual geral de redação. 2. ed. rev. aum. São Paulo: Folha de S. Paulo, 1987.

GIACOMOZZI et al. Dicionário de gramática. São Paulo: FTD, 2004.

LAURENS, Camille. Parenthèse(s). In: DURRENMATT, Jacques. (Org.). La ponctuation. Besançon: La Licorne, 2000.

LAURIA, Maria Paula Parisi. A pontuação. 3. ed. São Paulo: Atual, 1989. (Tópicos de linguagem)

OLIVEIRA, Maria Bernadete Fernandes de. Bakhtin e a cultura contemporânea: sinalizações para a pesquisa em Lingüística Aplicada. In: Rev. ANPOLL, n.13, p. 105-121, jul./dez. 2002.

SILVA, Anderson C. A pontuação e os efeitos de sentido: um estudo sob o viés bakhtiniano. Taubaté, 2009. 147f. Dissertação (Mestrado em Linguística Aplicada). Programa de Pós-Graduação em Linguística Aplicada, Universidade de Taubaté, Taubaté, 2009.

SILVERSTONE, Roger. Por que estudar a mídia? São Paulo: Editora Loyola, 2002.

VOLOSHINOV, V. N. O discurso na vida e o discurso na arte. Tradução para uso didático por C. Tezza e C. A. Faraco. [s.d.].

Recebido em 8 de janeiro de 2010. Aprovado em 5 de julho de 2010. 